\title{
ANALISIS TINGKAT PENCAHAYAAN RUANG KELAS STUDI KASUS : RUANG KELAS BAGIAN CONTROL ROOM PADA SUBBIDANG SARANA DAN PRASARANA PENGEMBANGAN SUMBER DAYA MANUSIA DAN INFORMASI PUSAT PENGEMBANGAN SUMBER DAYA MANUSIA, MINYAK DAN GAS BUMI (PPSDM MIGAS)
}

\author{
Yogie Budi Prakoso \\ Fakultas Teknik, Program Studi Teknik Industri \\ Universitas Negeri Sebelas Maret \\ Email: yogiebudip95@gmail.com \\ Muhammad Hisjam \\ Fakultas Teknik, Program Studi Teknik Industri \\ Universitas Negeri Sebelas Maret \\ Email: hisjam@uns.ac.id
}

\begin{abstract}
ABSTRAK
Analisis tingkat pencahayaan ruang kelas perlu dilakukan untuk mengetahui tingkat pencahayaan yang sudah ada, apabila dibawah standar yang ditentukan maka dapat menyebabkan kerusakan mata dan apabila diatas standar maka ruang kelas akan terlalu terang. Studi kasus dilakukan di ruang kelas bagian control room pada subbidang sarana dan prasarana pengembangan sumber daya manusia dan informasi PPSDM Migas. Penelitian bertujuan untuk mengetahui kondisi pencahayaan dan menentukan kesesuaian dengan SNI 03-6575-2001. Pengukuran dilakukan dalam tiga waktu berbeda yakni pagi hari (09.0010.00), siang hari (14.00-15.00), dan malam hari (20.00-21.00) untuk didapatkan intensitas pencahayaan rata-rata. Pengukuran tingkat pencahayaan dilakukan sesuai dengan metode pengukuran SNI 16-70622004 dan menggunakan batas tingkat pencahayaan minimal sesuai standar SNI 03-6575-2001. Diperoleh hasil bahwa tingkat pencahayaan rata-rata maksimum ruang kelas pada pagi hari, siang hari dan malam hari masing-masing adalah 84,33 lux, 88,5 lux, dan 123 lux. Nilai-nilai tersebut belum memenuhi standar SNI 03-6575-2001 yang ditentukan yakni sebesar 250 lux untuk ruang kelas yang berarti bahwa diperlukan perbaikan pada sistem pencahayaan ruang kelas dengan menambah jumlah lampu pada titiktitik yang ditentukan.
\end{abstract}

Kata kunci: tingkat pencahayaan, SNI 16-7062-2004, SNI 03-6575-2001, lux.

\begin{abstract}
Classroom lighting level analysis needs to be done to determine the level of existing lighting, if below the standard specified then it can cause eye damage and if above the standard then the classroom will be too bright. The case study was conducted in the control room classroom in the sub-field of human resources development and infrastructure facilities and information of PPSDM Migas. The objective of this research is to know the condition of lighting and to determine conformity with SNI 03-6575-2001. Measurements are done in three different times ie morning (09.00-10.00), noon (2:00 pm to 3:00 pm), and evening (20:00 to 21:00) to get the average lighting intensity. Measurement of the lighting level is performed in accordance with the method of measuring SNI 16-7062-2004 and using minimum lighting level limits according to SNI 03-6575-2001 standards. The results show that the average maximum average classroom lighting levels in the morning, day and night are 84.33 lux, 88,5 lux, and 123 lux respectively. These values have not met the specified standard SNI 03-6575-2001 which is 250 lux for the classroom which means that it needs improvement on the classroom lighting system by increasing the number of lamps at the specified points.
\end{abstract}

Keywords: level of lighting, SNI 16-7062-2004, SNI 03-6575-2001, lux.

\section{PENDAHULUAN}

Basuki dan Susilowati (2005:40) memberi pengertian sebagai berikut : "Lingkungan kerja adalah segala sesuatu yang berada di lingkungan yang dapat mempengaruhi baik secara langsung maupun tidak 
langsung seseorang atau sekelompok orang di dalam melaksanakan aktivitasnya.[1] Sedangkan menurut Parmonangan Manurung (2010) memberi pengertian bahwa "kenyamanan visual terkait dengan cahaya alami yang membantu manusia dalam mengakses informasi visual tanpa mengganggu indera visual manusia. Kondisi visual yang terlalu gelap karena kurangnya cahaya akan menciptakan ketidaknyamanan bagi indera visual. Ketidaknyamanan ini juga akan mempengaruhi persepsi visual manusia terhadap lingkungan visual manusia terhadap lingkungan visualnya."[4] Sedangkan menurut Grandjean (1993) menjelaskan bahwa pencahayaan tidak terlepas dari kenyamanan kerja, sekalipun hal tersebut dilakukan di dalam ruang kelas. Penerangan yang buruk dapat mengakibatkan kelelahan mata karena efisiensi kerja mata yang berkurang, keluhan pegal di daerah mata dan sakit kepala di sekitar mata serta kerusakan indra mata". [2]

Terdapat dua sumber pencahayaan yaitu sumber cahaya alami yang berasal dari alam dan sumber cahaya buatan yang dihasillkan dari peralatan yang dibuat manusia. Pencahayaan alami berasal dari sinar matahari yang masuk ke dalam ruang bangunan melalui bukaan pada bangunan dan sangat dipengaruhi oleh posisi bangunan terhadap posisi matahari, sedangkan pencahayaan buatan berasal dari lampu dengan berbagai jenis yang dapat dipilih sesuai kebutuhan. Ruang kelas sebagai salah satu ruang yang mengatur aktivitas belajar di sekolah memiliki arti penting bagi siswa dalam membantu kegiatan belajar sehingga mampu meningkatkan perkembangan ilmu pengetahuan serta menambah tingkat kecerdasan. Selain itu kondisi ruang kelas sangat berperan penting dalam memberikan kenyamanan terhadap penggunanya.

Ruang kelas di control room PPSDM Migas merupakan ruang kelas yang digunakan mahasiswa atau siswa yang sedang melakukan magang untuk melakukan aktivitas belajar yang membutuhkan penerangan yang memadai. Proses pembelajaran di ruang kelas tersebut merupakan salah satu strategi untuk mencapai tujuan mahasiswa maupun siswa yang sedang magang. Untuk mencapai tujuan tersebut akan sangat mengganggu apabila kondisi pencahayaan tidak sesuai standar yang ditentukan. Oleh karena itu, dilakukan pengamatan, pengukuran dan analisis tingkat pencayahaan baik pada pagi hari, siang hari maupun malam hari untuk mendapat gambaran dari kondisi pecahayaan rata-rata ruang kelas tersebut yang kemudian dibandingkan dengan standar yang sudah ditentukan. Menurut Standar Nasional Indonesia SNI 03-6575-2001, kuat pencahayaan minimum yang direkomendasikan untuk ruang kelas adalah 250 lux.

\section{MATERIAL DAN METODE}

Penelitian pencahayaan alami pada ruang kelas dilakukan dengan memanfaatkan cahaya matahari yang masuk melalui pintu kaca di depan kelas dan jendela kaca bening yang tertutup tirai berwarna krem yang terdapat pada sisi utara dan selatan ruangan. Sedangkan untuk pencahayaan buatan menggunakan lampu TL 2x18 Watt berjumlah 6 buah yang terletak 3 meter dari lantai. Intensitas pencahayaan pada bidang kerja yaitu pada meja belajar yang diukur dengan menggunakan luxmeter pada jarak $85 \mathrm{~cm}$ dari lantai. Denah ruang, profil ruang kuliah dan desain penelitian diberikan pada gambar 1 dan gambar 2 . Pengukuran juga dirancang dengan mengikuti standar pengukuran pencahayaan dalam ruang seperti yang tertuang dalam SNI 16-7062-2004 untuk kategori penerangan umum. Waktu pengukuran dilakukan dalam 3 waktu untuk mengetahui instensitas rata-rata pencahayaan setiap harinya yakni pada pagi hari (09.0010.00 WIB), siang hari (14.00-15.00 WIB) dan malam hari (20.00-21.00) pada saat cuaca cerah dan pada setiap titik dilakukan 3 kali pengukuran. Data pengukuran yang diperoleh kemudian dirata-ratakan untuk setiap lajur titik penelitian dan diolah menggunakan software surfer versi 10 untuk kemudian dibandingkan dengan nilai standar pencahayaan ruang kuliah dalam SNI. Faktor-faktor yang mempengaruhi nilai pencahayaan yang terukur juga akan dianalisis. 




Gambar 1. 2D Denah Ruang Kelas

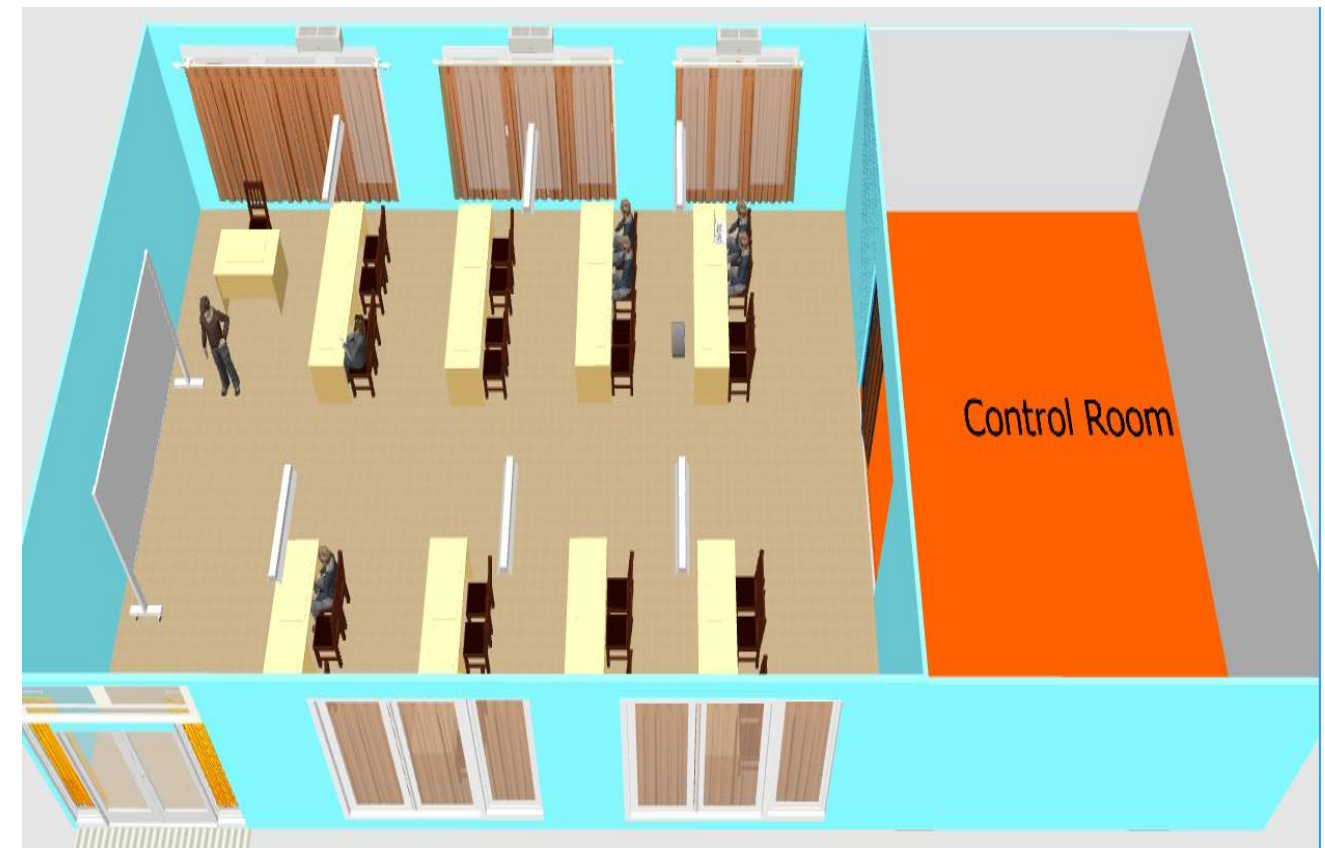

Gambar 2. 3D Ruang Kelas

Pengukuran intensitas cahaya pada ruang kelas ini menggunakan metode sesuai dengan standar SNI 16-7062-2004. Ruang kelas berukuran $11,7 \mathrm{~m}$ x 8,1 m sehingga memiliki luas 94,77 $\mathrm{m}^{2}$. Karena ruang kelas memiliki luas lebih antara $10-100 \mathrm{~m}^{2}$, maka penentuan titik ukur intensitas cahaya untuk penerangan umum menggunakan titik potong horizontal panjang dan lebar stasiun berjarak 3 meter. Titik pengukuran intensitas cahaya untuk penerangan umum pada ruang kelas dapat dilihat pada Gambar 3. 


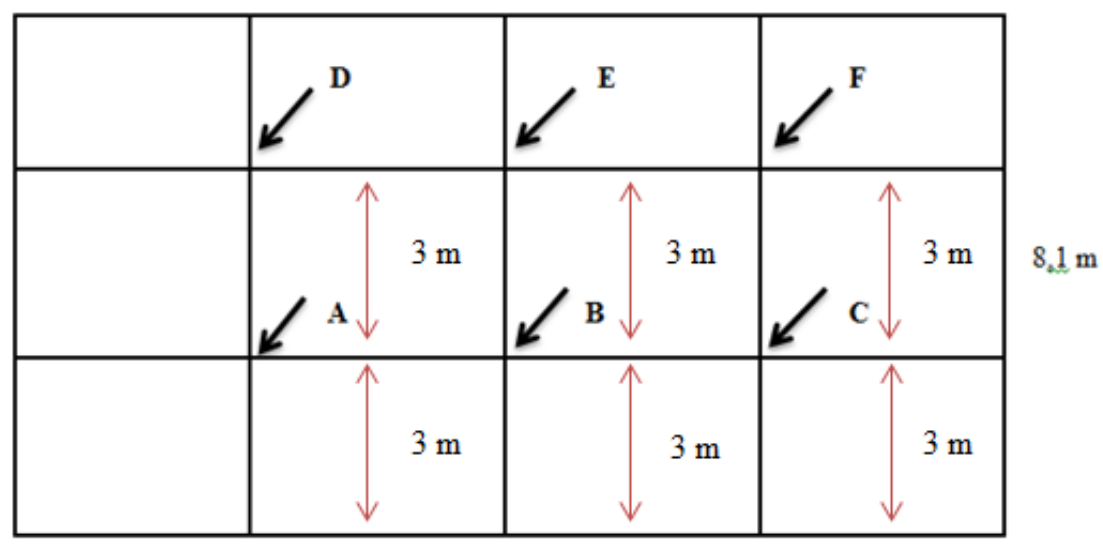

$11,7 \mathrm{~m}$

Gambar 3. Titik Pengukuran Intensitas Cahaya Umum Ruang Kelas

\section{HASIL DAN PEMBAHASAN}

\subsection{Hasil Pengukuran}

Tabel 1. Hasil pengukuran intensitas cahaya umum ruang kelas pagi hari

\begin{tabular}{|c|c|c|c|c|c|}
\hline \multirow{2}{*}{ No } & \multirow{2}{*}{ Titik Pengukuran } & \multicolumn{3}{|c|}{ Pengukuran Jam 09.00 - 10.00} & \multirow{2}{*}{$\begin{array}{c}\text { Rata-Rata } \\
\text { (lux) }\end{array}$} \\
\hline & & P1 (lux) & P2(lux) & P3 (lux) & \\
\hline 1 & $\mathrm{~A}$ & 110 & 109 & 107 & 108.67 \\
\hline 2 & B & 64 & 58 & 60 & 60.67 \\
\hline 3 & $\mathrm{C}$ & 53 & 50 & 51 & 51.33 \\
\hline 4 & $\mathrm{D}$ & 105 & 105 & 103 & 104.33 \\
\hline 5 & $\mathrm{E}$ & 100 & 103 & 104 & 102.33 \\
\hline 6 & $\mathrm{~F}$ & 76 & 81 & 79 & 78.67 \\
\hline \multicolumn{5}{|c|}{ Rata-Rata Intensitas Cahaya (lux) } & 84.33 \\
\hline
\end{tabular}

Berdasarkan tabel 1 dapat diketahui bahwa rata-rata pencahayaan tertinggi adalah pada titik A yang bernilai 108,67 lux. Sedangkan rata-rata pencahayaan terendah adalah pada titik C yang bernilai 51,33 lux. Rata-rata intensitas cahaya keseluruhan bernilai 84,33 lux dimana nilai tersebut belum memenuhi SNI 03-6575-2001 yakni sebesar 250 lux untuk ruang kelas.

Tabel 2. Hasil pengukuran intensitas cahaya umum ruang kelas siang hari

\begin{tabular}{cccccc}
\hline \multirow{2}{*}{ No } & \multirow{2}{*}{ Titik Pengukuran } & \multicolumn{3}{c}{ Pengukuran Jam 14.00 - 15.00 } & Rata-Rata \\
\cline { 3 - 5 } & & P1 (lux) & P2 (lux) & P3 (lux) & (lux) \\
\hline 1 & A & 127 & 122 & 120 & 123 \\
2 & B & 53 & 58 & 49 & 53.33 \\
3 & C & 31 & 41 & 50 & 40.67 \\
4 & D & 120 & 126 & 117 & 121 \\
5 & E & 111 & 109 & 105 & 108.33 \\
6 & F & 87 & 85 & 82 & 84.67 \\
\hline \multicolumn{5}{c}{ Rata-Rata Intensitas Cahaya (lux) } \\
\hline
\end{tabular}

Berdasarkan tabel 2 dapat diketahui bahwa rata-rata pencahayaan tertinggi adalah pada titik A yang bernilai 123 lux. Sedangkan rata-rata pencahayaan terendah adalah pada titik C yang bernilai 40,67 lux. Rata-rata intensitas cahaya keseluruhan bernilai 88,5 lux dimana nilai tersebut belum memenuhi SNI 036575-2001 yakni sebesar 250 lux untuk ruang kelas. 
Tabel 3. Hasil pengukuran intensitas cahaya umum ruang kelas malam hari

\begin{tabular}{cccccc}
\hline \multirow{2}{*}{ No } & Titik Pengukuran & \multicolumn{2}{c}{ Pengukuran Jam 20.00 - 21.00 } & \multirow{2}{*}{$\begin{array}{c}\text { Rata-Rata } \\
\text { llux) }\end{array}$} \\
\cline { 3 - 4 } & P1 (lux) & P2 (lux) & P3 (lux) & 124 \\
1 & A & 120 & 125 & 127 & 117.67 \\
2 & B & 118 & 120 & 115 & 120.67 \\
3 & C & 119 & 127 & 116 & 125.67 \\
4 & D & 121 & 125 & 131 & 127 \\
5 & E & 123 & 134 & 124 & 124.33 \\
6 & F & 112 & 135 & 126 & 123.22 \\
\hline
\end{tabular}

Berdasarkan tabel 3 dapat diketahui bahwa rata-rata pencahayaan tertinggi adalah pada titik D yang bernilai 127 lux. Sedangkan rata-rata pencahayaan terendah adalah pada titik B yang bernilai 117,67 lux. Rata-rata intensitas cahaya keseluruhan bernilai 123,33 lux dimana nilai tersebut belum memenuhi SNI 03-6575-2001 yakni sebesar 250 lux untuk ruang kelas

Catatan:

P1 : Pengukuran Pertama

P2 : Pengukuran Kedua

P3 : Pengukuran Ketiga

Setelah dilakukan pengumpulan data, langkah selanjutnya adalah melakukan pengolahan data. Pengolahan data ini didukung dengan menggunakan software Surfer versi 10. Tahap pertama dari pengolahan data ini adalah penentuan titik $(0,0)$. Pada tahap kedua dilakukan penentuan koordinat titik ukur berdasar titik pengukuran intensitas cahaya yang telah dibuat pada pengumpulan data. Setelah itu dilakukan tahap terakhir dari pengolahan data yaitu pemetaan titik ukur intensitas cahaya. Adapun penjelasan penentuan titik $(0,0)$ terdapat pada Gambar 4 .

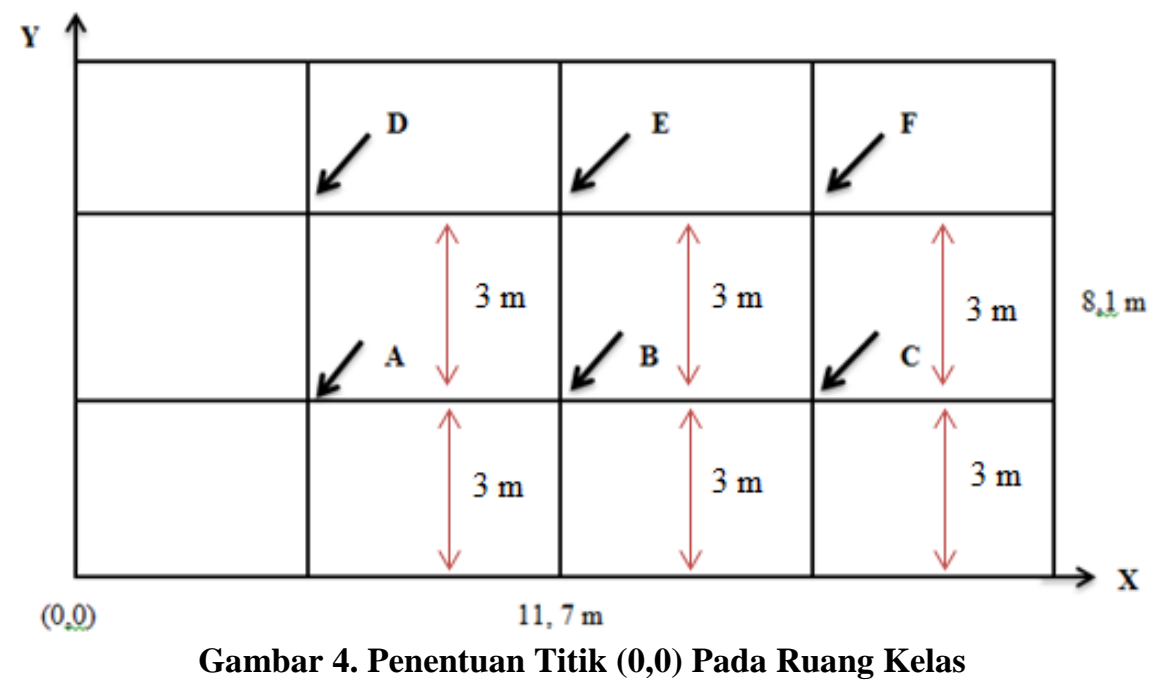

Dari gambar 4 diketahui bahwa titik $(0,0)$ dimulai dari pojok kiri bawah atau pada kenyataannya titik $(0,0)$ diambil dari sisi selatan gedung dekat pintu masuk yang selanjutnya ditentukan titik-titik berukuran tiga meter sebagai titik pengukuran. Setelah dilakukan penentuan titik $(0,0)$, tahap selanjutnya adalah penentuan koordinat titik ukur. Penentuan koordinat titik sumbu $\mathrm{x}$ dan sumbu $\mathrm{y}$ didapat berdasarkan panjang dan lebar ruang kelas. Koordinat titik z didapat dari rata-rata intensitas cahaya pada titik ukur tersebut. 
Tabel 4. Koordinat titik ukur ruang kelas pada pagi hari

\begin{tabular}{cccc}
\hline \multirow{2}{*}{ Titik Ukur } & \multicolumn{3}{c}{ Jam 09.00-10.00 } \\
\cline { 2 - 4 } & $\mathbf{x}$ & $\mathbf{y}$ & $\mathbf{z}$ \\
\hline A & 3 & 3 & 108.67 \\
B & 6 & 3 & 60.67 \\
C & 9 & 3 & 51.33 \\
D & 3 & 6 & 104.33 \\
E & 6 & 6 & 102.33 \\
F & 9 & 6 & 78.67 \\
\hline
\end{tabular}

Tabel 5. Koordinat titik ukur ruang kelas pada siang hari

\begin{tabular}{cccc}
\hline \multirow{2}{*}{ Titik Ukur } & \multicolumn{3}{c}{ Jam 14.00-15.00 } \\
\cline { 2 - 4 } & $\mathbf{x}$ & $\mathbf{y}$ & $\mathbf{z}$ \\
\hline A & 3 & 3 & 123 \\
B & 6 & 3 & 53.33 \\
C & 9 & 3 & 40.67 \\
D & 3 & 6 & 121 \\
E & 6 & 6 & 108.33 \\
F & 9 & 6 & 84.67 \\
\hline
\end{tabular}

Tabel 6. Koordinat titik ukur ruang kelas pada malam hari

\begin{tabular}{cccc}
\hline \multirow{2}{*}{ Titik Ukur } & \multicolumn{3}{c}{ Jam 20.00-21.00 } \\
\cline { 2 - 4 } & $\mathbf{x}$ & $\mathbf{y}$ & $\mathbf{z}$ \\
\hline A & 3 & 3 & 124 \\
B & 6 & 3 & 117.67 \\
C & 9 & 3 & 120.67 \\
D & 3 & 6 & 125.67 \\
E & 6 & 6 & 127 \\
F & 9 & 6 & 124.33 \\
\hline
\end{tabular}

Ketiga tabel diatas menunjukkan sumbu x sebagai titik horizontal atau panjang kelas, sumbu y sebagai titik vertikal atau lebar kelas serta koordinat titik z didapat dari rata-rata intensitas cahaya pada titik ukur tersebut.

Setelah ditentukan titik $(\mathrm{x}, \mathrm{y}, \mathrm{z})$ maka hal yang dilakukan selanjutnya adalah mengolah data tersebut dengan software Surfer versi 10 untuk mengetahui distribusi pencahayaan pada pagi hari, siang hari dan malam hari, sehingga didapatkan hasil seperti dibawah. 


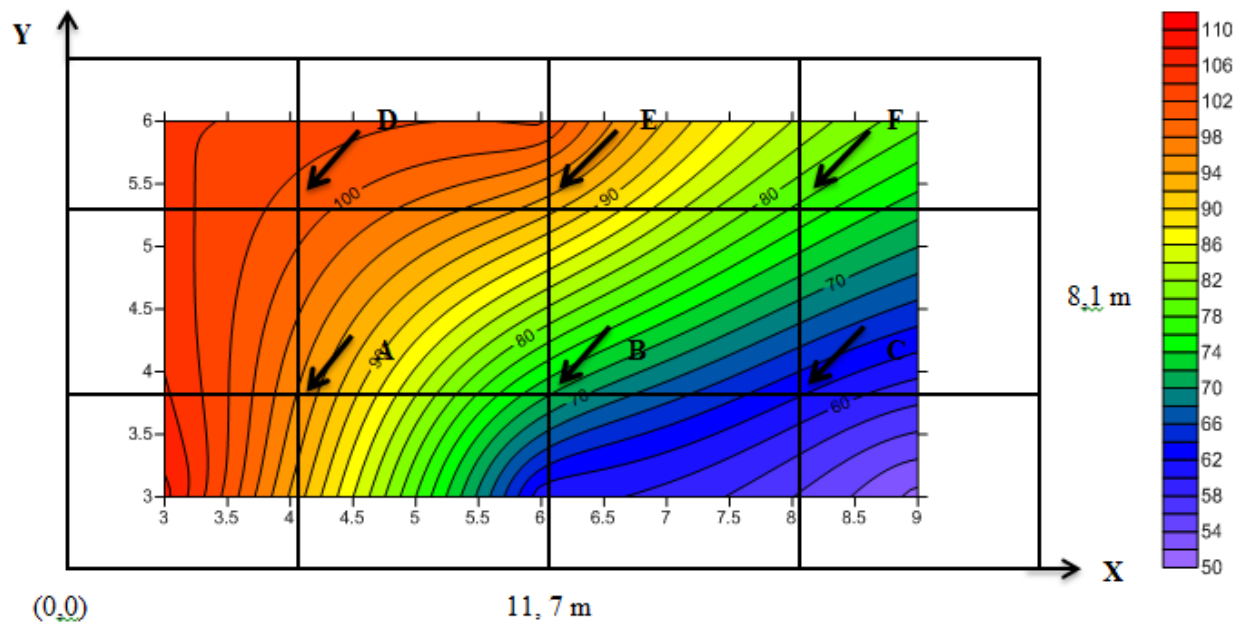

Gambar 5. Distribusi Pencahayaan Ruang Kelas pada Pagi Hari
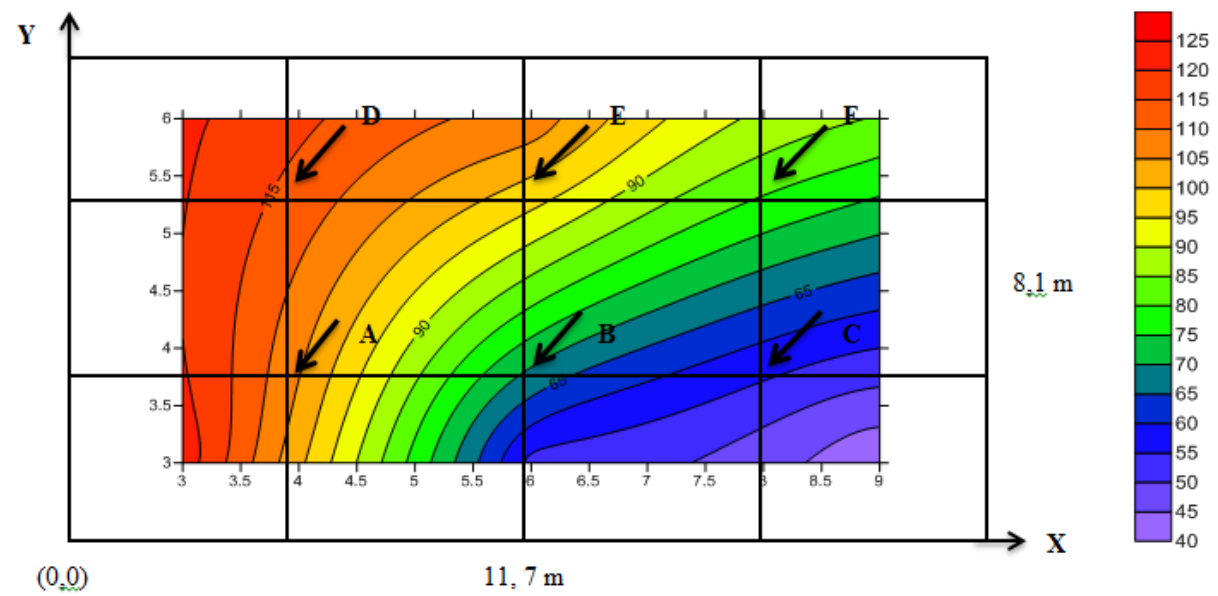

Gambar 6. Distribusi Pencahayaan Ruang Kelas pada Siang Hari
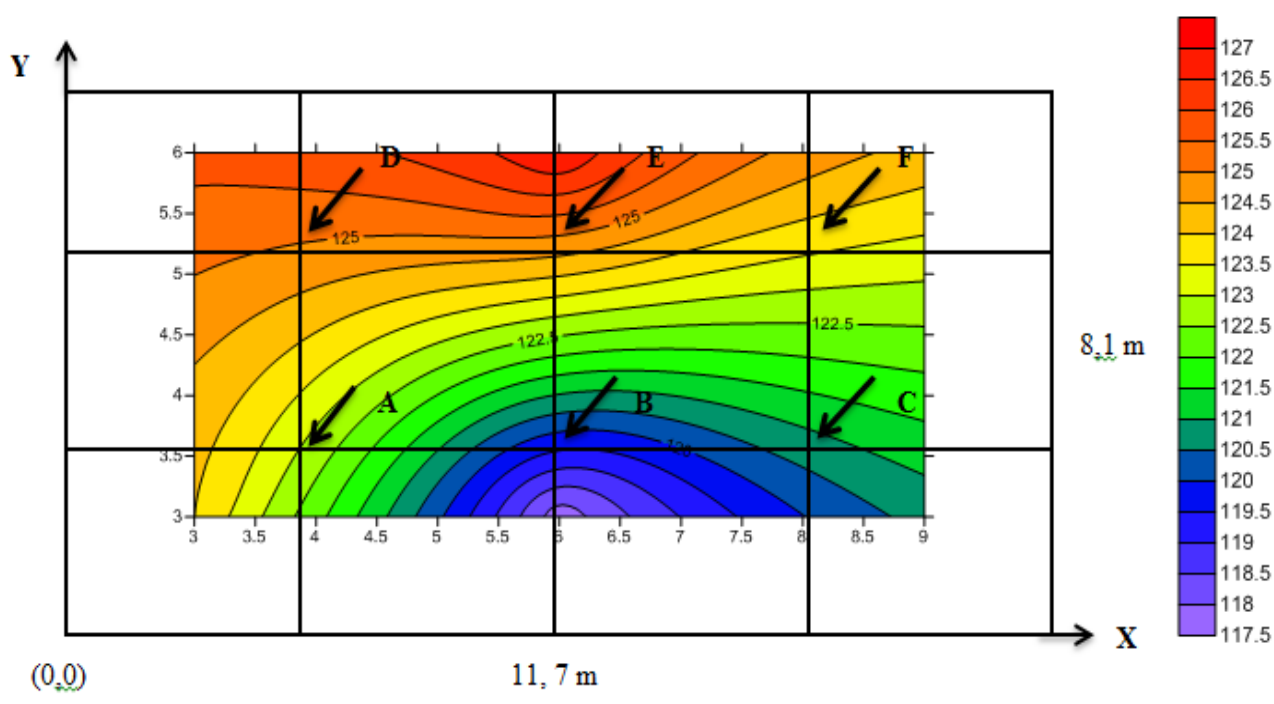

Gambar 7. Distribusi Pencahayaan Ruang Kelas pada Malam Hari

Dari tiga gambar distribusi pencahayaan hasil dari software surfer versi 10 diatas dapat diketahui titik-titik mana saja yang membutuhkan pencahayaan lebih besar pada waktu pagi, siang maupun malam hari. Semakin terang warna pada suatu titik, maka semakin kecil penambahan pencahayaan yang dibutuhkan, begitu pula sebaliknya. Titik-titik yang memerlukan penambahan pencahayaan yang lebih besar dari titik-titik lainnya yakni titik B dan C. 


\subsection{PEMBAHASAN}

Hasil pengukuran tingkat pencahayaan pada pagi hari menunjukkan bahwa yang berada di atas standar minimal SNI 03-6575-2001 adalah sebanyak 0 titik. Artinya, intensitas cahaya ruang kelas pada pagi hari yang telah memenuhi standar SNI 03-6575-2001 yakni 250 lux hanya sebesar $0 \%$. Pada pagi hari sumber cahaya pada ruangan hanya mengandalkan cahaya alami yang berasal dari sinar matahari yang masuk dari jendela yang tertutup tirai warna krem dan pintu berbahan kaca di sebelah selatan gedung.

Pada malam hari nilai intensitas cahaya ruang pada siang hari yang berada di atas standar minimal SNI 03-6575-2001 adalah sebanyak 0 dari 6 titik. Artinya, intensitas cahaya ruang pada pagi hari yang telah memenuhi standar SNI 03-6575-2001 hanya sebesar 0\%. Tidak adanya jumlah titik yang memenuhi standar dapat disebabkan oleh dua hal, yaitu sedikitnya lokasi yang dapat memberikan sumber cahaya dan adanya penghalang sinar berupa tirai yang cukup tebal.

Sedangkan nilai intensitas cahaya ruang kelas pada malam hari yang berada di atas standar minimal SNI 03-6575-2001 adalah sebanyak 0 dari 6 titik. Artinya, intensitas cahaya ruang kelas pada malam hari yang telah memenuhi standar SNI 03-6575-2001 hanya sebesar $0 \%$. Hal ini disebabkan lampu TL 2x18 watt sebanyak 6 buah belum memenuhi standar yang direkomendasikan.

\section{KESIMPULAN}

Dari hasil penelitian dapat disimpulkan bahwa rata-rata intensitas pencahayaan pada pagi hari, siang hari dan malam hari masing masing adalah 84,33 lux, 88,5 lux, dan 123 lux. Sedangkan menurut SNI 036575-2001, intensitas cahaya yang diperlukan untuk ruang kelas adalah sebesar 250 lux yang berarti kondisi sistem pencahayaan pada ruang kelas masih kurang memadai. Hal ini dibuktikan dengan mayoritas titik ukur dan rata-rata intensitas pencahayaan ruang kelas yang masih belum memenuhi standar pencahayaan yang telah direkomendasikan. Perbaikan sistem pencahayaan pada ruang kelas perlu dilakukan agar siswa dapat belajar tanpa mengalami gangguan aktivitas pembelajaran sehingga produktivitas siswa di ruang kelas tersebut menjadi optimal. Hal tersebut dapat dilakukan perusahaan dengan memberi instruksi untuk membuka tirai pada pagi dan siang hari agar mendapatkan pencahayaan alami dari matahari sebelum melakukan kegiatan pembelajaran dan pada malam hari dapat menambah lampu LED pada titik-titik yang dibutuhkan, penambahan lampu LED disamping agar lebih hemat energi juga membuat penerangan dalam ruang kelas dapat optimal.

\section{DAFTAR PUSTAKA}

[1] Basuki dan Susilowati. 2005. Dampak Kepemimpinan dan Lingkungan Kerja Terhadap Semangat Kerja

[2] Grandjean, E. 1993. Fitting the Task to the Man, 4th ed. Taylor and Francis Inc. London.

[3] Juningtyastuti, W. Agung, H. Fanny. 2012. "Optimisasi Kinerja Pencahayaan Buatan Untuk Efisiensi Pemakaian Energi Listrik Pada Ruangan Dengan Metode Algoritma Genetika”. Jurnal Momentum 13. 2, 40-49.

[4] Manurung, Parmongan. (2012). Pencahayaan Alami Dalam Arsitektur. Yogyakarta.

[5] P. Cok Gede Rai. 2006. "Pengaruh Penerangan Dalam Ruang Terhadap Produktivitas Kerja Mahasiswa Desain Interior. Jurnal Dimensi Interior 4. 2, 57-63.

[6] Pinangki. 2012. "Analisis dan Evaluasi Faktor Pencahayaan Pada Ruang Kuliah (Studi Kasus : Jurusan Teknik Mesin dan Industri Universitas Gadjah Mada Yogyakarta)". Jurnal Pascasarjana 2012.

[7] SNI 03-6575-2001, 2001, Tata Cara Perancangan Sistem Pencahayaan Buatan Pada Bangunan Gedung, Jakarta, BSN.

[8] SNI 03-6575-2004, 2004, Tata Cara Perencanaan Lingkungan Perumahan di Perkotaan Jakarta, BSN.

[9] Tongkukut, Seni Herlina J., Ari, As". 2016. "Analisis Tingkat Pencahayaan Ruang Kuliah Dengan Memanfaatkan Pencahayaan Alami Dan Pencahayaan Buatan”. Jurnal MIPA UNSRAT Online 5. 8, 108-112.

[10] Y. Muhammad. 2015. "Efek Pencahayaan Terhadap Prestasi Dan Kelelahan Kerja Operator". Jurnal Seminar Nasional IENACO 2015. 24-29. 